\title{
A double blinded randomized study on safety and efficacy between ultra sound guided and palpatory methods of axillary brachial plexus block for forearm surgeries
}

\author{
Amar Nath Gupta, Kamala Kanta Das \\ Assistant Professor, Department of Anaesthesiology, Gouri Devi Institute of Medical Sciences \& Hospital, Durgapur,
} West Bengal, India

Background: Regional anaesthesia like brachial plexus blocks are increasingly practiced now a day's for forearm surgery. A major limitation of brachial plexus block which may lead to unplanned general anesthesia is inconsistent block. Conventional nerve localization techniques which rely on surface anatomical landmarks may not provide satisfactory anesthesia. Aims and Objectives: In recent years, real time ultrasound guidance has been introduced as an aid to nerve localization. This study was planned to test the hypothesis that the quality of the axillary brachial plexus blockade guided by ultrasound was better than those using surface anatomical landmarks and produced fewer adverse effects and overall success in cases of forearm surgeries. Materials and Methods: After obtaining institutional ethics committee approval and written informed consent, 100 patients of American Society of Anesthesiologists grade I or II scheduled for forearm surgeries were included in the study and were randomly allocated into two groups. The brachial plexus blockade via axillary approach guided by ultrasound and traditional nerve localization techniques which rely on surface anatomical landmarks, patient report of paresthesia, and/or elicitation of a motor response by mechanical nerve stimulator or electric nerve stimulation with single-injection method was carried out in the two groups of patients respectively. Results: The patients $(n=100)$ predominantly female $(55 \%)$ with comparable demographic profile found to have statistically insignificant changes in the mean pulse rate, blood pressure, respiratory rate changes and oxygen saturation of hemoglobin during the surgical operations. Overall block success rate, blockade of each individual target nerve was better and procedural hazards were less in the ultrasound guided group.Conclusion: Real time ultra sound guided axillary nerve block is better than traditional palpable method with lesser adverse outcome.

Key words: Ultrasound, Brachial plexus, Axillary nerve block, Upper limb
Access this article online Website:

http://nepjol.info/index.php/AJMS DOI: 10.3126/ajms.v8i2.15361 E-ISSN: 2091-0576 P-ISSN: $2467-9100$

\section{INTRODUCTION}

Nowadays regional anaesthesia especially the brachial plexus block by axillary approach is an excellent anesthetic option for upper limb surgery. Long lasting pain relief, a low incidence of nausea and vomiting, and expedited hospital discharge are some of the clinical advantages for outpatients. ${ }^{1,2}$ But one of the major limitations of brachial plexus block which may lead to unplanned general anesthesia is inconsistent block. It leads to prolonged hospital stay, increase in the cost of therapy and other mental ailments of the patients as well as its family. Another limitation is the potential for procedure-related complications such as nerve injury and unintentional vascular puncture. ${ }^{3,4}$ The problem is mainly due to traditional nerve localization techniques which rely on surface anatomical landmarks, patient report of paresthesia, and/or elicitation of a motor response by mechanical nerve stimulator or electric nerve stimulation. 
In recent years, real time ultrasound guidance has been introduced as an aid to nerve localization ${ }^{5,6}$ for brachial plexus blockade. Ultrasound imaging techniques enable the anesthesiologist to secure an accurate needle position and monitor the distribution of the local anesthetic in real time, with the advantage of improving the quality of nerve block, shortening the latency of the block, and reducing the minimum volume required to obtain a successful nerve block. ${ }^{7-10}$ Axillary block has been practiced in the past by many workers like Leonard Brand and E. M. Papper, ${ }^{11}$ Captain Rudolph De Jong ${ }^{12}$ and they found it to be suitable due to better compliance of patients and relatively easier technique with fewer side effects like axillary hematoma, neurovascular injuries etc. While ultrasound has been reported to be useful for axillary block. ${ }^{13,14}$ Its safety and efficacy has not been evaluated much by well designed studies. Hence this prospective randomized double blinded study was aimed to test the hypothesis that the quality of the axillary brachial plexus blockade guided by ultrasound was better than those using surface anatomical landmarks and produced fewer adverse effects and overall success in cases of upper limb surgeries.

\section{MATERIALS AND METHODS}

After obtaining approval from the institutional ethics committee, a written informed consent was obtained from( $\mathrm{n}=100)$ patients classified as American Society of Anesthesiologists (ASA) Grade I or II of either sex aged between 25 and 60 years scheduled for elective orthopedic and soft tissue surgery of forearm and were included in the study. Unwilling patients, patients with history of allergy to local anesthetics, infection at local site of block, progressive neurological disorders, severe kidney dysfunction, severe liver dysfunction, history of bleeding disorders history of convulsions, bleeding disorders, cardiac, respiratory, renal or liver ailment were excluded.

After securing an intravenous access with appropriate cannula, all patients were premedicated with glycopyrrolate $0.2 \mathrm{mg}$ intramuscularly 30 minutes before surgery prior to shifting in the operating room. All the patients were made aware of their pain assessment by $25 \mathrm{G} 2 \mathrm{~cm}$ needle prick. Sensory anesthesia to needle prick was assessed using a $25 \mathrm{G}$ needle and graded as $2=$ normal sensation, $1=$ decreased or dull sensation, $0=$ no sensation. Individual muscle groups were tested as follows: Thumb opposition (median nerve), little finger flexion and finger abduction-adduction (ulnar nerve) and wrist and elbow extension (radial nerve).

Non invasive monitors e.g.[ECG, Non invasive blood pressure (NIBP), pulse-oximeter] were attached and a baseline parameters ( $\mathrm{SpO}$ 2, pulse rate, blood pressure, and respiratory rate were recorded. The patients were then allocated to receive the axillary block either by conventional mechanical palpation of axillary artery method Group A $(n=50)$ or real time ultrasound guided Group $B(n=50)$ approach by permuted block randomization. All regional blocks were given by a qualified senior anesthesiologist using $30 \mathrm{ml}$ of bupivacaine hydrochloride $(0.5 \%)$ locally in the vicinity of nerve.

For blinding purposes, a "sham" ultrasound probe was applied to the axillary area and held by an assistant. The probe was connected to the ultrasound equipment in the stand-by mode. Assessment of the patients of both group and the data collection was done by another independent anesthesiologist.

For axillary approach the patient was held in the supine position with the arm to be blocked placed at a right angle to the body and the elbow flexed to 90 degrees. The dorsum of the hand was rested on the bed or pillow; hyper-abduction of the arm with placement of the hand beneath the patient's head was not allowed because this position frequently obliterates the pulse.

For conventional palpation method of blockade for Group A patients, axillary artery was palpated, and a line was drawn tracing its course from the lower axilla as far proximally as possible. The artery was then fixed against the patient's humerus by the index and middle fingers of the left hand, and a skin wheal was raised directly over the artery at a point in the axilla approximating the skin crease. Placement of the needle proximally and maintenance of distal pressure facilitate proximal spread of the solution. Paresthesia was sought with a 25G,2cm needle and a total of $30 \mathrm{ml}$ of the $0.5 \%$ bupivacaine was injected. If the musculocutaneous nerve was not blocked by the axillary approach then it was blocked by injection within the body of the coracobrachialis muscle or at the elbow superficially at the lateral aspect of the antecubital fossa just above the interepicondylar line. ${ }^{15}$

As soon as the anesthetic drug was injected for initiation of block, the time was noted as "zero time". Time of onset of sensory block in each group was recorded using needle prick in skin dermatomes by a $25 \mathrm{G}$ needle once in every 3 minutes for the first 30 minutes after injection and there after every 30 minutes till patient regained normal sensations. The same observer assessed the motor block at same time intervals.

Patients in Group B received an axillary block under ultrasound guidance using a linear 5-12 MHzprobe and Philips HDI 5000 unit (Philips Medical Systems ATL Ultrasound, Bothell, WA, USA). The probe surface was 
covered by a sterile transparent dressing and sterile gel was applied prior to scanning. Individual nerves, axillary vessels, and adjacent muscles (biceps, coracobrachialis and triceps muscles) were identified in a transverse view (Figure 1). The ultrasound probe was oriented consistently to display the biceps muscle on the left side of the sonogram screen (above the artery) and the triceps muscle on the right side [below the artery] (Figure 1). Location of individual nerves was recorded according to a schematic drawing of eight pie-chart sectors (Figure 2). ${ }^{16}$ The needle was advanced inline with the ultrasound beam until the needle tip was placed adjacent to each target nerve before local anesthetic was injected to produce a circumferential spread around each target nerve.

In this study the onset of sensory block was described from the time (in minutes) of injection of drug to time of first detection of diminished sensation and completion

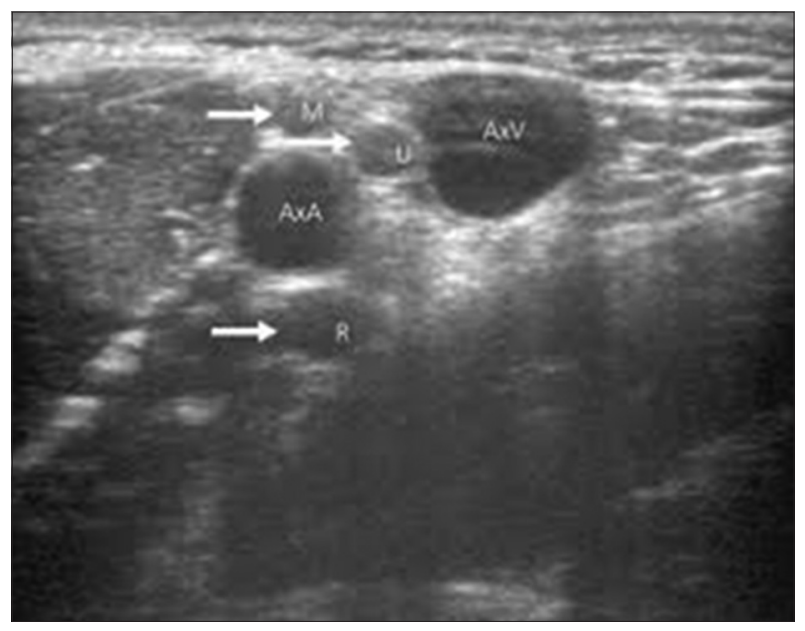

Figure 1: A transverse sonogram showing the median $(\mathrm{M})$, radial $(R)$ and ulnar $(U)$ ner ves around the axillary arter y $(A x A)$ axillary vein $(\mathrm{AxV})$ of sensory block was from the time of injection of drug to time of loss of pain on pinprick. Again onset of motor block was designated from the time of injection to time of first detection of diminished power and completion of motor block was from the time of injection of drug to time of complete loss of movement.

Duration of sensory blockade was the time in minutes from the onset of analgesia to the recurrence of pain to pin prick. Duration of motor blockade was the time in minutes from the onset of paresis to the recovery of motor movements.

The quality of sensory and motor block was studied and labeled as successful when the blocks were complete and failed when blocks were incomplete or totally absent. In those cases general anesthesia was given and was excluded from the study. Motor block was graded according to the movement of upper limb by the patient as: Grade 5-normal movement of upper limb, 4-movement against resistance, 3 -movement against gravity, 2-movement along gravity but not against resistance, 1 -flickering movement and 0 -no movement. A Grade of 3,2 or 1 was considered as partial block. A Grade of 0 was considered as complete motor paralysis i.e., the patient could not move his limb at all. A Grade of 2 to 5 motor activity after administration of block was considered as failure of block.

A blinded observer recorded the pulse rate, blood pressure, respiration rate and $\mathrm{SpO}_{2}$ at intervals of 5 minutes for initial 30 minutes then at every 15 minutes for up to 180 minutes. The patients were monitored for any complications like bradycardia, convulsions, restlessness, disorientation, drowsiness and any other complications. Fluid management was done depending upon fluid deficit, maintenance requirement, nature of operation, blood loss etc.

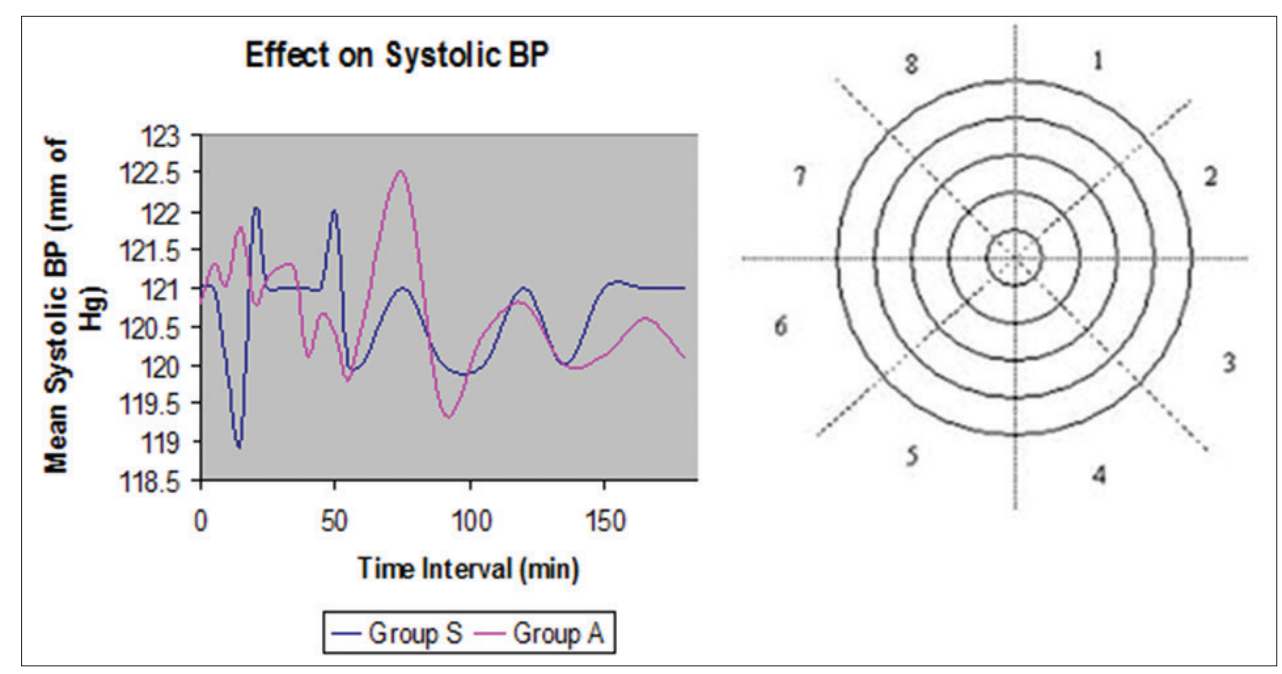

Figure 2: A schematic drawing of eight pie-chart sectors to describe nerve locations around the axillary artery 
Method of statistical analysis

The data were analyzed by using computer software Microsoft Excel and SPSS 12.0 for windows. Baseline comparability was ensured employing appropriate statistical tests. Group sizes (50 patients per group) were determined using the proportion sample size estimates (type 2 error $=80 \%$, type 1 error $=0.05)$ to detect a $20 \%$ difference in the rates of complete sensory block at $50 \mathrm{~min}$. Chi-square test was then employed to find the $\mathrm{p}$-value at various time intervals. All analysis was two sided and a $\mathrm{P}$ value of $<0.05$ was considered to be statistically significant. The final results were interpreted in tabular form.

\section{RESULTS}

The present study was conducted on $(n=100)$ consented patients aged between 25-60 years excluding the total failed blocks $(n=07)$ from both groups. Anesthetic failure was managed with supplemental intravenous analgesics or general anesthetics as appropriate.

There were no differences between the two groups with regard to height, weight, gender, age, duration of surgery or American Society of Anesthesiologists grades (Table 1). The distribution of age, sex, weight, mean duration of surgery was comparable between the two groups and was statistically insignificant. The mean pulse rate, blood pressure, respiratory rate changes and oxygen saturation of haemoglobin during the surgical operations were statistically insignificant in patients recruited for either technique of block (Figures $3 \mathrm{a}$ and b, 4, 5).

Patients in Groups B had a higher overall block success rate $86.1 \%$ than Group A $66.8 \%(\mathrm{P}=0.01$ and 0.05 respectively, (Table 2). Blockade of each individual target nerve was also more successful in Groups B after 30 min (Table 2). The median nerve was most commonly visualized in sectors 7 and 8 (55\%), the ulnar nerve in sectors 1 and $2(82 \%)$ and the radial nerve in sectors 3 and $4(68 \%)$.

The radial nerve was the most frequently missed nerve in all three study groups (Table 2). The block procedure time was significantly shorter in Group B (9.8 $\pm 3.0 \mathrm{~min}$ vs $11.9 \pm 5.4$ min for Group A (Table 2). Major complications like unintentional intravascular injection and persistent neurological deficit was not recorded. A transient post-block paresthesia ( $<4$ days) was observed in $(n=10)$ patients in both Group A and $(n=9)$ in Group B. Local bruising was detected in $(n=6)$ and $(n=2)$ patients in Group A and B, respectively. Local axillary pain or discomfort was noted in $(n=12)$ and $(n=5)$ patients in Group A\&B respectively.

\begin{tabular}{|c|c|c|c|}
\hline SI no. & Demographic profile & $\begin{array}{c}\text { Group A } \\
(n=50)\end{array}$ & $\begin{array}{c}\text { Group B } \\
(n=50)\end{array}$ \\
\hline \multirow[t]{3}{*}{1} & Gender & & \\
\hline & Male & $23(46 \%)$ & $22(44 \%)$ \\
\hline & Female & $27(44 \%)$ & $28(56 \%)$ \\
\hline \multirow[t]{5}{*}{2} & Age (yrs) & & \\
\hline & $21-30$ & 18 & 16 \\
\hline & $31-40$ & 14 & 12 \\
\hline & $41-50$ & 13 & 11 \\
\hline & $51-60$ & 05 & 11 \\
\hline \multirow[t]{5}{*}{3} & Weight (kg) & & \\
\hline & $41-50$ & 05 & 05 \\
\hline & $51-60$ & 20 & 19 \\
\hline & $61-70$ & 18 & 22 \\
\hline & $71-80$ & 07 & 04 \\
\hline \multirow[t]{8}{*}{4} & $\begin{array}{l}\text { Surgical procedures: (No. } \\
\text { of cases) }\end{array}$ & & \\
\hline & Lower Ulna Excision & 4 & 3 \\
\hline & $\begin{array}{l}\text { Open reduction \& internal } \\
\text { fixation-Ulna }(U)\end{array}$ & 10 & 12 \\
\hline & $\begin{array}{l}\text { Open reduction \& internal } \\
\text { fixation-Radius }(R)\end{array}$ & 3 & 2 \\
\hline & $\begin{array}{l}\text { Open reduction \& internal } \\
\text { fixation- } U+R\end{array}$ & 18 & 15 \\
\hline & Radial Head Excision & 4 & 7 \\
\hline & Skin Graft & 6 & 6 \\
\hline & Tendon Repair & 5 & 5 \\
\hline \multirow[t]{5}{*}{5} & $\begin{array}{l}\text { Duration of } \\
\text { surgery (minutes) }\end{array}$ & & \\
\hline & $46-60$ & $14(28 \%)$ & $10(20 \%)$ \\
\hline & $61-75$ & $17(34 \%)$ & $16(32 \%)$ \\
\hline & $76-90$ & $10(20 \%)$ & $13(26 \%)$ \\
\hline & $91-105$ & $9(18 \%)$ & $11(22 \%)$ \\
\hline
\end{tabular}

\begin{tabular}{|c|c|c|}
\hline & $\begin{array}{c}\text { Group A } \\
(n=46)^{\star}\end{array}$ & $\begin{array}{l}\text { Group B } \\
(n=47)^{*}\end{array}$ \\
\hline Block procedure time (min) & $11.9 \pm 4.2$ & $9.8 \pm 4.0$ \\
\hline $\begin{array}{l}\text { Complete sensory block in all } \\
\text { three nerves at } 30 \mathrm{~min}\end{array}$ & $66.8 \%$ & $86.1 \%$ \\
\hline $\begin{array}{l}\text { Successful surgical anesthesia } \\
\text { without supplementation }\end{array}$ & $88 \%$ & $97.7 \%$ \\
\hline $\begin{array}{l}\text { Supplementation (General } \\
\text { anesthesia) }\end{array}$ & $4(8.6 \%)$ & $3(6.3 \%)$ \\
\hline \multicolumn{3}{|l|}{ Sensory block at $30 \mathrm{~min}$} \\
\hline Median nerve & $41(89.1 \%)$ & $43(91.4 \%)$ \\
\hline Ulnar nerve & $41(89.1 \%)$ & $44(93.6 \%)$ \\
\hline Radial nerve & $33(71.3 \%)$ & $39(82.9 \%)$ \\
\hline \multicolumn{3}{|l|}{ Motor block at $30 \mathrm{~min}$} \\
\hline Median nerve & $37(80.4 \%)$ & $44(93.6 \%)$ \\
\hline Ulnar nerve & $38(82.6 \%)$ & $45(95.7 \%)$ \\
\hline Radial nerve & $34(73.9 \%)$ & $41(87.2 \%)$ \\
\hline
\end{tabular}

* $(n=07)$ patients were excluded due to block failure

\section{DISCUSSION}

Ultrasound aided regional block is gradually being more acceptable though it requires investment of time and money for acquisition of new skills and equipments. It's a 

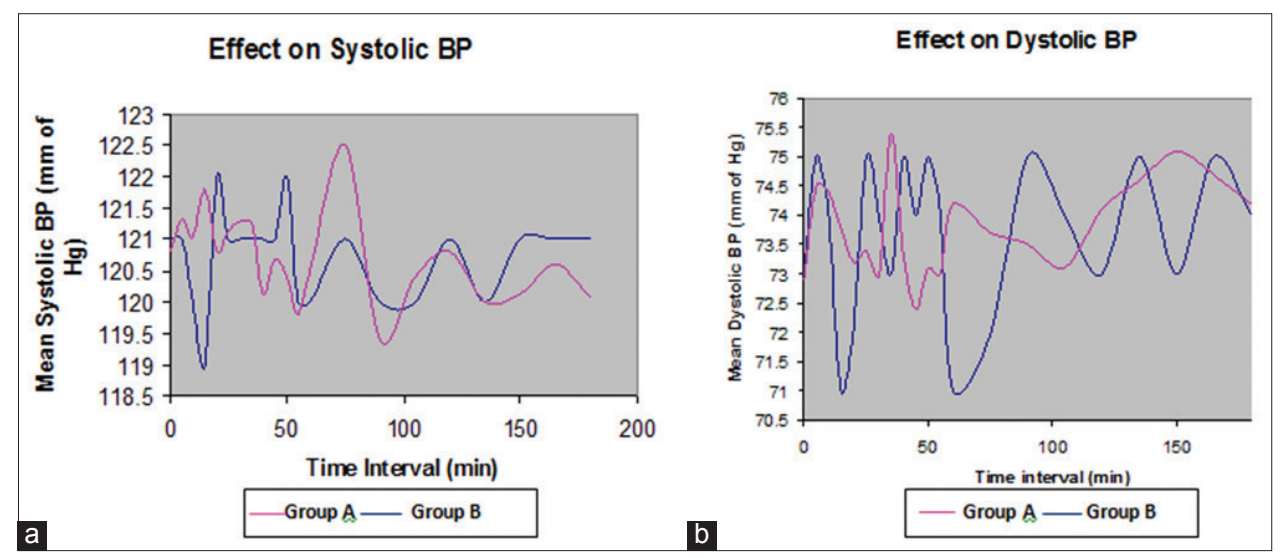

Figure 3: $(a$ and $b)$ Effects on systolic \& diastolic blood pressure during regional anesthesia among the study participants

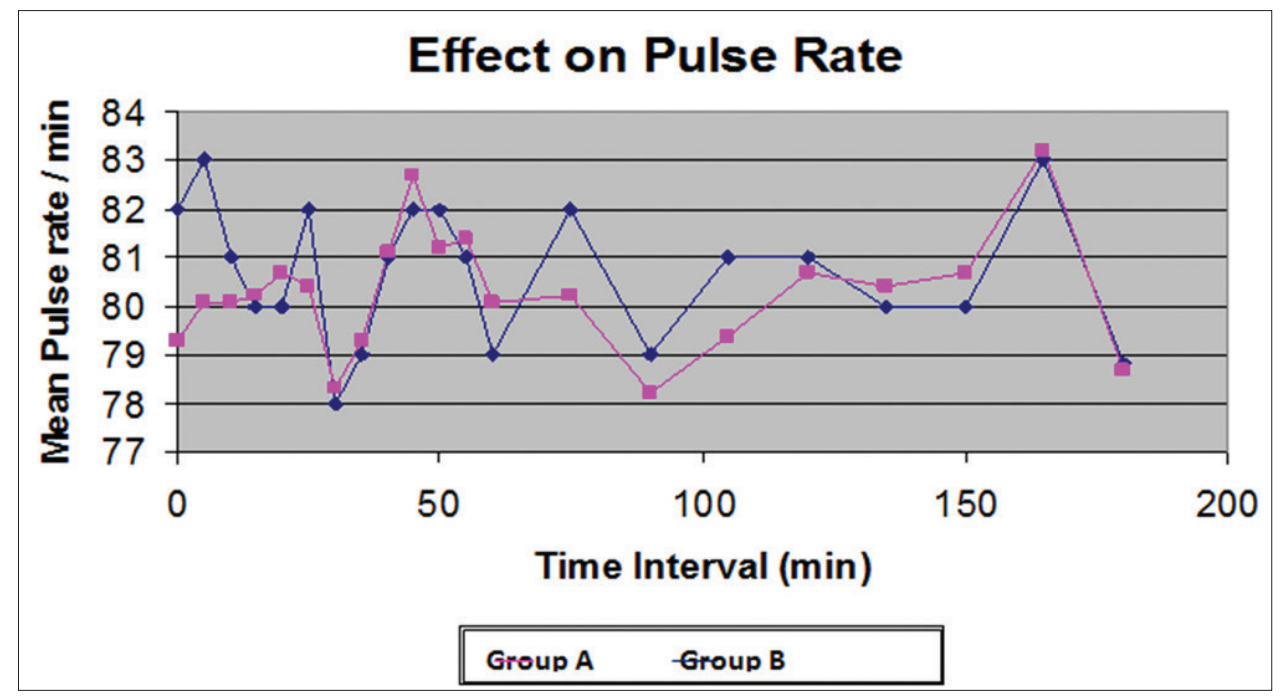

Figure 4: Effects on pulse rate during regional anesthesia among the study participants

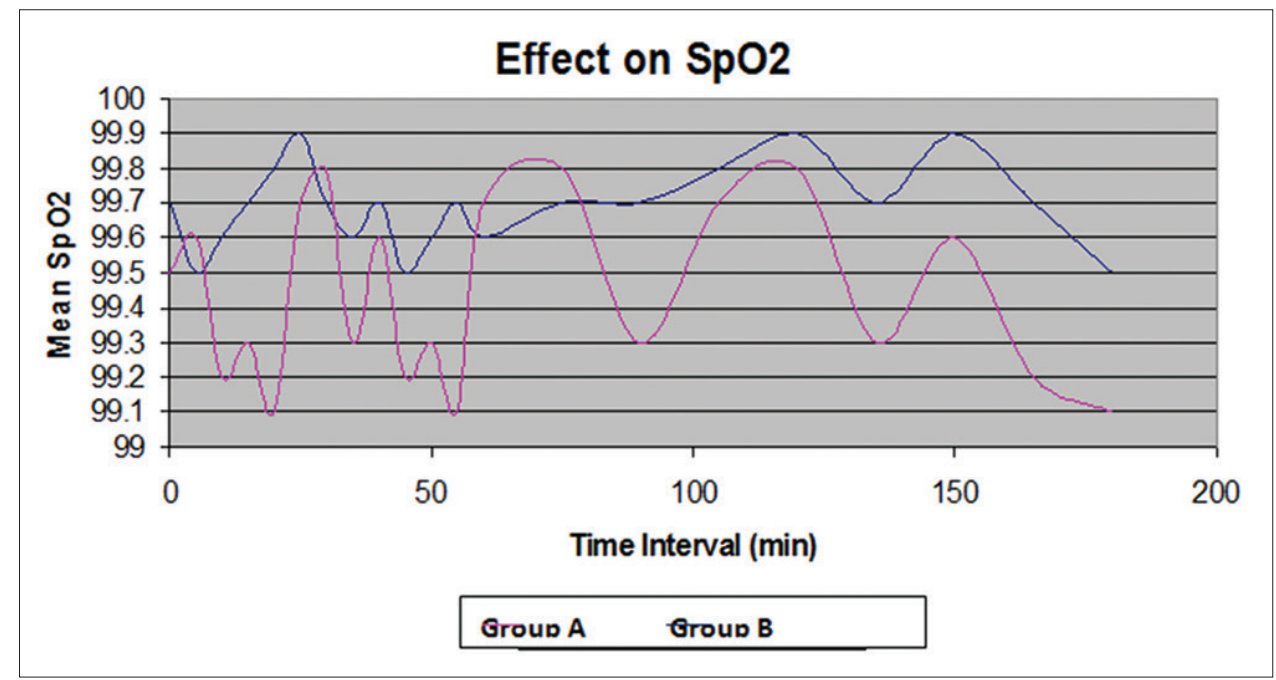

Figure 5: Effects on partial pressure of oxygen (SpO2) during regional anesthesia among the study participants

demand of the time for its inclusion in day to day procedure for regional block. In our study, successful block of the brachial plexus nerves was defined as anesthesia that was sufficient for a pain-free surgery without the need for supplemental anesthetics and our results suggest that ultrasound guidance improves the success rate of axillary 
brachial plexus block without an increase in procedure time when compared to conventional palpable method (successful surgical anesthesia without any supplementation Group B 97.7\% vs Group A 88\%). Though the block success rate was statistically insignificant in our study, it was comparable with the study of Vincent W. S. et al ${ }^{17}$ wherethey achieved a success of $95 \%$ and $85.5 \%$ among their study population. In this study the complete pinprick anesthesia in all three nerves i.e. medial, radial and ulnar was used as the definitive endpoint for block success, yieldinga lower block success rate $66.8 \%$ for the conventional palpable method. Among the earlier published earlier data of Williams et $\mathrm{al}^{10} \&$ Liu et al ${ }^{18}$, most of them failed to show any improved block success. Although the overall success rate was not statistically different in these studies, ultrasound guidance was reported to shorten block procedure time, ${ }^{10}$ hasten block onset, ${ }^{19}$ improve block quality, ${ }^{10}$ prolong block duration ${ }^{19}$ and decrease block related complications. ${ }^{18,20}$ which can be partially correlated with our study.

The accessibility to radial nerve was most challenging among the three nerves because of its deep location and poor visualization. This clarifies why the radial nerve was missed so often in our study (incomplete sensory anesthesia at 30 min: 17\%, 35\% in Group US and C respectively).

Supplementation of general anesthesia due to incomplete block or failure of block was almost similar in both the group $8.6 \%$ vs $6.3 \%$ respectively. Although the incidence of sensory block at 30 minutes was comparable between the two study groups, the incidences of motor block at 30 minutes was more in ultrasound guided group as compared to the conventional method. Also we failed to achieve 100\% success with ultrasound guided axillary block. This is likely to be due to mistaken identification of the nerve by ultrasound. Hence the skill of the anesthesiologist is a very vital issue which may influence the outcome of different techniques of brachial plexus block.

In contrast to our hypothesis, we failed to demonstrate a statistically significant higher block success rate when ultrasound was used as a confirmatory tool though the incidences of improve block quality, and decrease block related complications was established by using such devices.

\section{CONCLUSION}

The brachial plexus blockade via axillary approach guided by ultrasound with single-injection method offers excellent quality of sensory and motor block better to that of the conventional palpation method guided technique, with fewer adverse effects. Though the study was done on a limited sample of patients, a larger study group might reveal more encouraging results with more advanced study design. One important outcome of this research was the skill of the anesthesiologist engaged in the study which might greatly influence the outcome.

\section{REFERENCES}

1. Pavlin DJ, Rapp SE, Polissar NL, Malmgren JA, Koerschgen M and Keyes $H$. Factors affecting discharge time in adult outpatients. Anesth Analg 1998; 87: 816-826.

2. Chan VW, Peng PW, Kaszas Z, Middleton WJ, Muni R, Anastakis DG and Graham BA. A comparative study of general anesthesia, intravenous regional anesthesia,and axillary block for outpatient hand surgery: Clinical outcome and cost analysis. Anesth Analg 2001; 93: 1181-1184.

3. Ben David B and Stahl S. Axillary block complicated by hematoma and radial nerve injury. Reg Anesth Pain Med 1999; 24: 264-266.

4. Stan TC, Krantz MA, Solomon DL, Poulos JG and Chaouki K. The incidence of neurovascular complications following axillary brachial plexus block using a transarterial approach. A prospective study of 1,000 consecutive patients. Reg Anesth 1995; 20: 486-492.

5. Perlas A, Chan VW and Simons M. Brachial plexus examination and localization using ultrasound and electrical stimulation: A volunteer study. Anesthesiology 2003; 99: 429-435.

6. De Andres $\mathrm{J}$ and Sala-Blanch $\mathrm{X}$. Ultrasound in the practiceof brachial plexus anesthesia. Reg Anesth Pain Med 2002; 27: 77-89.

7. Marhofer $P$, Greher M and Kapral S. Ultrasound guidance in regional anaesthesia. $\mathrm{Br} J$ Anaesth. 2005; 94:7-17.

8. Grau T. Ultrasonography in the current practice of regional anaesthesia. Best Pract Res Clin anaesthesiol. 2005; 19:175-200.

9. Koscielniak-Nielsen ZJ. Ultrasound-guided peripheral nerve blocks: What are the benefits? Acta Anaesthesiol Scand. 2008; 52:727-737.

10. Williams SR, Chouinard P, Arcand G, Harris P, Ruel M, Boudreault D, et al. Ultrasound guidance speeds execution and improves the quality of supraclavicular block. Anesth Analg. 2003;97:1518-1523.

11. Leonard B and Papper EM. A comparison of supraclavicular and axillary technique for brachial plexus block. Anesthesiology $1961 ; 22: 2269$.

12. De Jong RH. Axillary block of the brachial plexus. Anesthesiology. 1961 Mar-Apr; 22:215-225.

13. Ting PL and Sivagnanaratnam V. Ultrasonographic study of the spread of local anaesthetic during axillary brachial plexus block. Br J Anaesth 1989; 63: 326-329.

14. Reed $\mathrm{J}$ and Leighton $\mathrm{S}$. Ultrasound facilitation of brachial plexus block. Anaesth Intensive Care 1994; 22: 499.

15. Miller, RD et al. Miller's Anesthesia, 7th ed, Churchill Livingstone: 2009: pp 1669.

16. Retzl G, Kapral S, Greher M and Mauritz W. Ultrasonographic findings of the axillary part of the brachial plexus. Anesth Analg 2001; 92: 1271-1275.

17. Chan VWS, Perlas A, McCartney JLC, Brull R, Xu D and Abbas $S$. Ultrasound guidance improves success rate of axillary brachial plexus block. Can J Aneth. 2007; 54: 3:176-182.

18. Liu FC, Liou JT, Tsai YF, Li AH, Day YY, Hui YL and Lui PW. Efficacy of ultrasound guided axillary brachial plexus block: $A$ comparative study with nerve stimulator-guided method. Chang 
Gung Med J 2005; 28: 396-402.

19. Marhofer P, Sitzwohl C, Greher M and Kapral S. Ultrasound guidance for infraclavicular brachial plexusanaesthesia in children. Anaesthesia 2004; 59: 642-646.
20. Soeding PE, Sha S, Royse CE, Marks P, Hoy G and Royse AG. $A$ randomized trial of ultrasound-guided brachial plexus anaesthesia in upper limb surgery. Anaesth Intensive Care 2005; 33: 719-725.

\section{Authors Contribution:}

ANG - Concept and design of the study, reviewed the literature, manuscript preparation and critical revision of the manuscript; KKD - Concept, review of literature and helped in preparing first draft of manuscript.

Source of Support: Nil, Conflict of Interest: None declared. 